\title{
Galactorrhoea following hypophysectomy in a boy with a prolactinoma
}

\author{
P. DANDONA \\ D.Phil., M.R.C.P. \\ J. MOHIUDDIN \\ M.D., M.R.C.P. \\ K. W. LINDSAY \\ Ph.D., F.R.C.S.
}

Metabolic Unit, Department of Chemical Pathology and Department of Neurosurgery, Royal Free Hospital and School of Medicine, Pond Street, London NW3 2QG.

\begin{abstract}
Summary
An 18-year-old boy with delayed puberty was found to have a large prolactinoma. Hypophysectomy led to a fall in serum prolactin concentration, although it remained markedly elevated. The introduction of replacement therapy, including testosterone, resulted in painful swelling of the breasts and galactorrhoea. Bromocriptine therapy resulted in a cessation of galactorrhoea and normalization of serum prolactin concentrations. The absence of galactorrhoea in association with an astronomical concentration of prolactin, and its onset in association with diminished prolactin concentrations following hypophysectomy and the introduction of testosterone therapy, indicate that galactorrhoea requires the presence of high prolactin concentrations to act on mature breast tissue. This would account for the rarity of galactorrhoea in prepubertal children with prolactinomas.
\end{abstract}

KEY WORDS: delayed puberty, obesity, bromocriptine.

\section{Introduction}

The occurrence of prolactinoma in boys is rare; what reports there are deal with boys with some evidence of puberty (Koenig, Zuppinger and Leichti, 1977; Slonim, Glick and Island, 1982). Its association with galactorrhoea in boys is even more unusual (Koenig et al., 1977; Van Meter et al., 1977). We describe here a prepubertal boy with a large prolactinoma in whom galactorrhoea developed following hypophysectomy and pituitary irradiation. We believe this case is unique in terms of the intriguing series of events. It is also important in illustrating a basic mechanism underlying the pathogenesis of

Correspondence: Dr P. Dandona, Metabolic Unit, Department of Chemical Pathology, Royal Free Hospital, Pond Street, London NW3 2QG. galactorrhoea; this would account for the rarity of this symptom in prepubertal children.

\section{Case history}

This 18-year-old boy was referred to the Metabolic Clinic on account of progressive obesity over the previous 4 years. Examination revealed an obese $\stackrel{\infty}{?}$ shy, short-statured boy with total absence of facal $\overrightarrow{10}$ pubic, axillary and body hair. He had infanfiles genitalia and a feminine voice. Visual fields and optic discs were normal and no other neurological defieip was present.

Investigations revealed normal haematological in dices, plasma urea, electrolytes and creatinine. Serumb thyroxine $(40 \mathrm{nmol} / \mathrm{l})$ and free thyroxine index were low; serum thyrotrophin (TSH) was not elevated (1. 70 $\mathrm{mu} / \mathrm{l})$ and did not rise following intravenous thyrotrophin releasing hormone (TRH). Serum testoster one was $2 \cdot 1 \mathrm{nmol} / 1$. Serum prolactin was $6,300 \mathrm{mu} / \mathrm{p}$. (normal range: 150-400 mu/1). Luteinizing hormone (LH) and follicle stimulating hormone (FSH) were low at 2 and $1 \mathrm{u} / 1$ respectively, and did not rises following the injection of gonadotrophin-releasing hormone (GnRH). Insulin-induced hypoglycaemia produced no increase in growth hormone concentra-tion $(<0.5 \mathrm{mu} / 1$ throughout the test. A low random? cortisol $(107 \mathrm{nmol} / 1)$ increased to a maximum of $232 \mathrm{z}$ nmol/1. The 24-hour urinary cortisol was low at 33 nmol. Skull X-ray with tomography showed anf enlarged pituitary fossa with a double floor. $\mathrm{Com}_{7}$ puted tomographic (CT) scan showed a small supra sellar extension of the pituitary tumour. Perimetry confirmed normal visual fields.

A transphenoidal hypophysectomy was per을 formed, and a large tumour, shown on histology to be a chromophobe adenoma, was removed. This was followed by irradiation of the pituitary fossa. Four weeks later, a reassessment of pituitary function 
confirmed panhypopituitarism, but serum prolactin was still high $(4350 \mathrm{mu} / \mathrm{l})$. At this stage, the patient was feeling extremely weak and faint in the afternoons. A random cortisol concentration in serum was $75 \mathrm{nmol} / \mathrm{l}$. Hormone replacement therapy with thyroxine $(0.15 \mathrm{mg}$ daily), hydrocortisone $(20 \mathrm{mg}$ in the morning and $10 \mathrm{mg}$ in the evening) and testosterone (primoteston $250 \mathrm{mg}$ intramuscularly every month) was commenced. Four weeks later, the patient's subareolar breast tissue increased in size bilaterally, and became nodular and painful. Spontaneous flow of milk started soon afterwards, and the patient had to change four pads every day to prevent his shirt from getting soaked in milk. Serum prolactin was still markedly elevated $(4,350 \mathrm{mu} / \mathrm{l})$. Bromocriptine therapy was commenced; the dose was increased to $10 \mathrm{mg}$ daily. Galactorrhoea gradually ceased and the breast swelling subsided. Serum prolactin had dropped to $139 \mathrm{mu} / 1$. Serum oestradiol concentration was 140 pmol/1 5 days after the injection of testosterone, and fell to $61 \mathrm{pmol} / 1$ six weeks after the injection.

\section{Discussion}

The onset of painful gynaecomastia and galactorrhoea in this patient occurred within 4 weeks of the introduction of testosterone therapy against the background of hyperprolactinaemia. The persistence of hyperprolactinaemia following hypophysectomy is consistent with the non-removal of a small segment of the tumour; this is common following surgery for macroprolactinomas (Spark et al., 1982). In a boy who had no evidence of puberty at the time of clinical presentation and subsequent hypophysectomy, the introduction of testosterone clearly induced a rapid proliferation of breast tissue and its maturation into a secretory organ. This study shows clearly that the presence of a significant concentration of testosterone-or of oestrogens derived from it-is essential for the maturation of breast tissue to occur, and for galactorrhoea to manifest. Prolonged exposure to astronomical concentrations of prolactin is obviously not a sufficient stimulus on its own. That this patient's gynaecomastia/galactorrhoea was not merely a response to the onset of artificially induced puberty (following testosterone therapy) is proved by the disappearance of these symptoms following bromocriptine therapy, which resulted in the suppression of prolactin secretion.

It may be argued that since cortisol and thyroxine replacement therapy were started at the same time as testosterone, the maturation of breast tissue, and hence galactorrhoea, could be due to these hormones rather than to testosterone or the oestrogens derived from it. This is a theoretical possibility; however, the role of adrenal steroids in human lactation is not established (Aragona and Friesen, 1979) and diminished adrenocortical function is not an established cause either of delayed puberty or the lack of breast development. As far as the effect of diminished thyroid function on the breast is concerned, it usually causes galactorrhoea, rather than a cessation of breast development. In fact, hypothyroidism can often present with galactorrhoea as the initial symptom (Semple et al., 1983). It is unlikely, therefore, that either thyroxine or hydrocortisone replacement therapy contributed significantly to the pathogenesis of galactorrhoea in this patient.

The infrequent occurrence of galactorrhoea in boys with prolactin-secreting tumours is possibly the consequence of arrested puberty and the non-proliferation/maturation of breast tissue. Treatment of the prolactin-secreting tumour (through a combination of surgery, radiotherapy and bromocriptine) following which an increase in endogenous testosterone secretion or the introduction of exogenous testosterone does not result in gynaecomastia/galactorrhoea if the prolactin concentration has been normalized.

The other important lesson from this case is that in boys with delayed puberty, a minimal biochemical screen including the serum concentrations of gonadotrophins and prolactin must be performed. Elevated gonadotrophins point to non-development or atrophy of testes (including chromosomal abnormalities) and a markedly elevated prolactin to a prolactinoma. Delayed puberty would thus be diagnosed by exclusion in boys with normal gonadotrophins and prolactin. In the above mentioned patient, simple serum tests would have led to the diagnosis of prolactinoma several years earlier, with the possibility of preserving some pituitary reserve.

\section{References}

ARAGONA, C. \& FRIESEN, H.G. (1979) Lactation and galactorrhoea. In: Endocrinology, Vol. III. (Ed. L.J. de Groot) p. 1613. Grune and Stratton, New York.

KOENIG, M.P., ZUPPINGER, K. \& LEICHTI, B. (1977) Hyperprolactinaemia as a cause of delayed puberty: successful treatment with bromocriptine. Journal of Clinical Endocrinology, 45, 825.

Semple, C.G., Beastall, G.H., Teasdale, G.H. \& Thomson, J.A. (1983) Hypothyroidism presenting with hyperprolactinaemia. British Medical Journal, 286, 1200.

Slonim, A.E., Glick, A.D., Island, D.P. \& Kasselberg, A.G. (1982) Hyperprolactinaemia associated with advanced puberty in a male. Journal of Pediatrics, 101, 236.

Spark, R.F., Wills, C.A., O'Reilly, G., Ransil, B.J. \& BerGLUND, R. (1982) Hyperprolactinaemia in males with and without pituitary macroadenomas. Lancet, if, 129.

Van Meter, Q.L., Gareis, F.J., HaYes, J.W. \& Wilson, C.B. (1977) Galactorrhoea in a 12-year old boy with chromophobe adenoma. Journal of Pediatrics, 90, 756.

(Accepted 29 June 1983) 